\title{
Guided reading
}

\section{Being mindful of the reading processing of new entrants in Aotearoa New Zealand primary schools}

\author{
JUDY AITKEN, HELEN VILLERS, AND JANET S. GAFFNEY
}

\section{KEY POINTS}

- Children's early development of processing systems for reading may be at risk if they are plunged prematurely into guided reading at entry to school.

- Understanding and skill is required to introduce a story to new-entrant children in a manner that will lead to children's independent reading of the new text.

- $\quad$ Guided reading lessons should be structured to facilitate opportunities to teach for processing in reading.

- Children's early development of processing systems for reading may be at risk if they become confused by the teacher's language of instruction in beginning guided reading. 
Guided reading is an established and important approach in the pedagogical repertoire of teachers in Aotearoa New Zealand. Despite evidence suggesting that a strong foundation of literacy learning must be built before introducing guided reading, early initiation to this most intensive form of reading instruction has become commonplace. This study examined the guided reading practices of three exemplary literacy teachers working with small groups of the most recent new entrants in their classes. We investigated what teachers understand and what they do to support young children to construct effective processing systems for reading. Teachers were observed and video recorded as they taught three guided reading lessons with 5 year olds at entry to school, and subsequently interviewed about their teaching decisions using stimulated-video recall. Running Records of continuous text were administered as a window to monitor children's change over time in their reading processing. Finely nuanced descriptions and analyses of the teachers' professional knowledge, pedagogical approaches, and student outcomes have significant implications for early literacy learning and teaching.

Teacher Katy holds up the new book, and as the three children crane forward to take a closer look she draws their attention to the title and cover illustration. "I think you might know this girl," she smiles.

Recognition sparks on faces. Madalyn shares what she already knows about Sam. Katy then reveals a brief synopsis of the story. "Bingo wants to play with Sam and with her toys and her farm.” Amber's eyes light up with anticipation, and she makes an impulsive prediction. Katy questions, "Do you? Why do you think that?" As she turns the pages, Katy explores the plot, weaving in the language of the text. At one point, with her finger brushing the text, she prompts, "And Sam said to Bingo .. ? 'No, Bingo, no!", and the children spontaneously chime in. ${ }^{1}$

Our purpose was to explore teachers' understandings about how to support the development of young children's processing systems for reading. ${ }^{2}$ Like Madalyn and Amber, most children in Aotearoa New Zealand begin school on or near their fifth birthday and they must be enrolled from their sixth. Staggered entry allows new-entrant teachers flexibility to focus attention upon individual children and to make careful observations of their early interactions with print.

Children vary in the time they take to make the transition to school, and they may benefit from a variety of supportive opportunities if they are to adapt to the social and instructional protocols of the classroom and extend their emerging literacy through purposeful talking, listening, reading, and writing. Educators are keenly aware that failure to get underway with reading can have serious consequences for children's ability to build strong foundations for a lifetime of learning (Clay, 1991, 2001, 2014). As a result, new-entrant teachers have tended to initiate guided reading from the point of school entry, using the first simple texts, perceiving that an immediate start in formal instruction will leverage rapid progress. In fact, until a recent Ministry of Education retraction (Ministry of Education, 2014), the Literacy Learning Progressions (Ministry of Education, 2010) emphatically stated: "As soon as students start school, they begin reading texts at Magenta level" (Ministry of Education, 2010, p. 10). Some children, however, will find the transition to new-entrant classrooms more demanding than others and, despite quality teaching, may quickly fall behind (Clay, 2014). This can be particularly significant for children identified as priority learners; those less likely to experience success in New Zealand schools associated with Māori or Pasifika heritage, low socioeconomic background, or requiring special educational support (Education Review Office, 2012). The challenge for teachers is to support the early foundational learning of each child in their care to ensure each child builds an effective processing system for reading and writing as progress is made along individual pathways (Ministry of Education, 2003b, 2013b). 


\section{Foundational learning within an effective processing system for reading}

Clay (2010) described children's foundational learning as "discovering concepts about print, knowledge of the written code and seeing the symbols [letters] and patterns of symbols in print and looking at print according to the directional rules of our written language" (p. 38). In-the-head working systems that direct complex movement patterns for reading and writing are also an integral aspect of foundational learning (Clay, 2010, p. 38). Typically, in New Zealand classrooms a variety of formal early literacy instructional approaches are used to facilitate this foundational learning. These include key approaches such as shared reading and writing (collaborative approaches to text), language experience (shared, multisensory activities that create links between oral language, writing, and reading), listening to appealing picture books read aloud, drawing, singing, poetry and, importantly, engaging in purposeful oral language conversation and related activities (Ministry of Education, 2009a). These literacy events are often print based, but increasingly teachers are employing multimodal digital affordances to support young children's learning (McDowall, 2010). In all these myriad ways, teachers provide explicit teaching that is embedded in lively, enjoyable, and meaningful literacy experiences (Biddulph, 2002). Within this well-supported setting, concepts about print such as left-to-right reading and one-to-one matching are demonstrated, and letters, sounds, words and ideas are discussed and linked to children's lives. In this way, children's familiarity with book language increases, and their phonological awareness and word knowledge develops as the teacher draws their attention to text features, interesting ideas, and important concepts. As a result of consistent repeated actions, or practice, children give increased attention to the finer details of print (Smith \& Elley, 1997). Children develop these foundational understandings as by-products of their immersion in rich literacy activities. These are not concepts directly or explicitly taught before a child begins reading and writing (Clay, 2010, p. 12). Clay (2010) cautioned that unless children's foundational learning is established, instructional interactions around early texts are likely to confuse them.

\section{Teaching for an effective processing system through guided reading}

Guided reading is gradually added to the range of authentic literacy approaches likely to facilitate foundational learning. Guided reading in the New Zealand setting means the teacher selects and introduces a new book to a small group of children. Working in a small group enables the teacher to monitor each child reading the text individually. The teacher provides support when necessary to help each child gain control over the processes that lead to successful independent reading. Guided reading, then, assumes "a central role in leading students towards independence in reading" (Ministry of Education, 2003b, p. 96). Researchers in Aotearoa New Zealand (Boocock 2012; Education Review Office, 2009; McNaughton, Phillips \& MacDonald, 2003) and internationally (Ford \& Opitz, 2008; McKay, 2004) have highlighted issues with the implementation of guided reading. In New Zealand, guided reading is typically undertaken using the Ready to Read series of appealing, high interest, graded texts, issued free to every primary school in the country. Recently, the series underwent a review (Ministry of Education, 2014) to ensure that the design of the texts and their purpose remained current and continued to meet the diverse needs and interests of New Zealand children. The review led to alterations in the design and levelling of texts, as well as clarifications around the "usual business" of guided reading as a key instructional practice. When used alongside other approaches, guided reading is deemed to directly support the development of processing systems for young children (Hancock 2015; Ministry of Education, 2014; Biddulph, 2002). Importantly, the revisions clarify the point at which teachers might begin to engage a child in guided reading. In the recent past, teachers' decisions about when to initiate guided reading with individual children may have been overridden by the pressure to ensure their students met the National Standards in reading (Ministry of Education, 2009b). Although we agree with the notion of a common achievement goal for all children, we strongly contend that teaching, especially at entry to school, needs to be responsive to individual competencies. Immersing children in set learning sequences or demanding instructional protocols in their early days at school creates a risk that unequal starting points will lead to the exacerbation and persistence of inequitable outcomes.

\section{An exploratory study}

Given the vital nature of each child's early learning, we needed to look more closely at guided reading practices with newcomers in their first year of school. How are teachers creating learning opportunities that enhance or inhibit children's development of processing systems for reading? 
Two central questions guided this study:

I. What knowledge and understandings about processing systems for reading are reflected in teachers' implementation of guided reading in the first year of school?

2. How does guided reading influence children in the first year of school to build processing systems for reading?

We used a descriptive case-study design (Stake, 2010) in the context of 3 new-entrant classrooms in which 5-yearold children could be observed constructing processing systems for reading as they began to engage in formal literacy instruction. The teachers (Anna, Julia, Katy) from 3 different schools, were nominated by their principals and each accepted the invitation to participate in the study. Data-gathering measures included semistructured teacher interviews, video-recorded observations of guided reading lessons, stimulated-recall interviews, and Running Records (Clay, 2005).

At the beginning of the study, the first author conducted semistructured interviews with each teacher to gather their perspectives and understandings on literacy learning and teaching, and about their guided-reading practice in particular. The first author then observed and video recorded 3 guided reading lessons of each teacher at 2-week intervals. For the purposes of the study, the cohort observed $(N=14)$ comprised the children who were the most recent entrants in each teacher's class, and part of a newly formed guided-reading group. Video clips of lessons were replayed to each teacher soon after each guided-reading lesson. This procedure stimulated the teachers' reflections on the viewed lesson and their rationale for teaching decisions. Following each observed lesson, the first author administered a Running Record to every child in each group to gather information about change over time in their processing.

The semistructured and stimulated-recall interviews were transcribed. Repeated viewings of the videorecorded lessons led to the identification of intriguing short clips of teaching interactions that piqued our curiosity. The 42 Running Records were analysed. These data were integrated and synthesised for each teacher as a way to capture changes in teaching and children's learning over time.

Importantly, the unit of analysis for this study was the observable and inferable development of children's processing systems for reading. Thus, the case in this case-study is "the development of processing in reading", rather than a focus on individual teachers, children, or schools. This approach allowed us to capture, analyse, and report exemplars of processing across teachers and across children.

\section{Findings and implications}

We found that there were risks attached to an immediate start to guided reading. Lesson structure and content, as well as the instructional language and protocols within guided reading lessons, were sometimes confusing for young children. These early transitional challenges may contribute to a delay in children's development of processing systems for reading, defeating teachers' best intentions to gain momentum through a fast start. Exploration of data patterns across teachers allowed us to consider guided-reading practices that either contributed to or inhibited children's development of processing systems for reading. Important considerations have emerged that are worthy of further professional inquiry, discussion, and future research.

\section{Challenge "business as usual" by choosing a more optimal time to introduce a child to guided reading}

The practice of introducing all children to guided reading within the first days of school contradicts prevailing advice. Scholars focused on guided reading consistently support the view of a gradual rather than peremptory introduction to this intensive instructional approach (Clay, 2010; Doyle, 2015, Fountas \& Pinnell, 2012). As previously indicated, a recent review of the Ready to Read series has addressed this issue (Hancock, 2015; Ministry of Education, 2014). One rationale for a more gradual introduction is that children need to have developed competencies in meaningful and productive oral language and be able to interact effectively alongside their peers within the guided-reading context (Fountas \& Pinnell, 2012; Jeurissen \& Burt, 2015; Richardson, 2009). Usual practice appears to have had a considerable influence on teaching decisions that influence how effectively children's processing systems for reading are facilitated.

The written code can be puzzling for young learners when they begin formal instruction. Researchers have long described important understandings about literacy that children need to acquire in order to lay a foundation for learning to read. Doyle (2015) claimed that when children read the first little books in guided reading they need to know "Where to look, what to look for and how to fixate and move eyes across sentences and individual words within printed text" (p.17). This involves coordinating body, hand, and eye movements. When children control these movements, they have in place an early working system for processing text (Boocock, 2012). These early behaviours can be learnt by new- 
entrant children as they begin to engage in the formal literacy activities of the classroom, but not necessarily in guided reading. In this study however, some children were engaged in guided reading, as soon as they entered school.

When asked to explain their decision to get children underway with guided reading in the first days at school, teachers responded that their early focus was on helping children learn to attend to print. All three teachers shared the expectation that children needed to be able to read at the Green level after one year at school to meet the National Standard, and that moving quickly towards this goal was essential (Ministry of Education, 2009). They acknowledged that their selections of simple repetitive texts at Magenta level were based on helping children establish one-to-one matching, directionality, and knowledge of concepts about print. Their rationales indicated they were using guided reading to help children build foundational habits for early reading. This contradicted advice that success in early reading is accounted for by children already having foundational learning underway (Clay, 2014). Although this study was conducted before the withdrawal of the National Standards reporting requirements in 2017, it is likely that well-intentioned teachers nationwide have maintained this practice.

\section{Implications for learning and teaching}

McNaughton $(2002,2011)$ cautioned that teachers of new-entrant children need to be keen observers of their transition into literacy, and to be especially attentive to those who may be confused by early encounters with print. Introducing children to guided reading should be based on two actions: careful observation; and response to individual children's literacy learning profiles, with particular reference to the language resources that children bring from home. It is argued that a peremptory rather than gradual introduction to guided reading may significantly influence the progress of new-entrant children who are least prepared for engagement in the literacy practices of the classroom. Confusion may lead to reduced self-efficacy and loss of motivation very early in a child's school journey (Johnston \& Allington, 1991; Ministry of Education, 2013a). This notion resonates with Rubie-Davies (2015) finding that a link exists between ability grouping and achievement. These aggregating barriers to achievement are most disturbing in the case of priority learners whose literacy learning disparities with other children are already apparent at school entry (Clay, 1991, 2014; McNaughton, 2002, 2011; Ministry of Education, 2013b).

\section{Introduce new texts in accessible and engaging ways}

Observations of guided-reading lessons in this study showed that introducing new stories in ways that facilitated children's independence in reading is a complex practice. A pivotal element in a guided-reading lesson rests in creating interest, exploring, and explaining features of the text, including new words and concepts, and drawing on children's own experiences (Fountas \& Pinnell, 1996; Richardson, 2009). Recently, Ready to Read has placed more emphasis on teachers providing a rich introduction. This change was due to anecdotal reports that story introductions were limiting rather than facilitating children's independent reading of the new text (Ministry of Education, 2014).

The purpose of an introduction is to make a new text immediately accessible so children are able read it independently on the first attempt. As they read, they learn how to process by problem solving using the information in the text. The teacher monitors individual reading and intervenes with supportive prompts if necessary (Ministry of Education, 2003a; Schwartz, 2005). However, McKay (2004) pointed out that the traditional interpretation of monitoring is "hearing children read" (p. 36). This occurs when children read in unison, or individually in a "round robin" sequence. It is argued that both methods make monitoring individual reading more difficult for teachers and reduces the opportunity for children to take responsibility for problem solving and meaning making.

Helpful teaching techniques for introducing a new story aimed at facilitating independent first reading of the text are identified in this study. They include minimal teacher talk, very few questions, expressive use of face and voice, pauses for effect, encouragement to children to become active participants, and interactions underpinned by momentum and energy. When techniques like these were used, story introductions tended to be no more than 3 minutes; long enough to motivate children but short enough to maintain their full engagement (Ministry of Education, 2002). Despite the brevity of the introduction, it is possible for teachers to weave knowledge of sounds and letter features into the flow of the discussion about the story, and to anticipate new or challenging print features to assist problem solving and independence during the first reading (Fountas \& Pinnell, 2012).

\section{Implications for learning and teaching}

One implication of the current study is that teacher introductions to new texts vary and different teacher interpretations of this step in the lesson can influence 
children's independence. Some instructional interactions tended to focus on meaning, although more often, others tended to focus on sounds, letters and word-level skills, limiting the children's engagement with meaning. This latter approach to text may reflect a view that learning to read is dependent on a hierarchical instructional sequence where children will find reading difficult until they know or can draw on their knowledge of sounds and letters to solve the words. Children may, under these circumstances, develop a mindset that reading is only about attending closely to the print. However, it can be argued that an independent reading of a new text is less likely if meaning does not provide a guide for processing. Calls for teachers to provide "rich" introductions to new text (Ministry of Education, 2014; Hancock, 2015) could be problematic, however, in light of variations in theoretical and pedagogical emphases in this country. How might the notion of a rich introduction be interpreted by teachers who typically emphasise meaning, compared with teachers who typically emphasise words, letters and sounds? Is a trade-off between sounds and letters and meaning necessary, or desirable? Alternatively, is it possible for teachers, within the natural interactions around the story, in combination with attention to one or two features of the print, to maintain the flow of the story (Tunmer, Chapman, Greany, Prochnow, \& Arrow, 2013)?

\section{Structure guided-reading lessons so there is time for processing}

Teachers in this study structured their guided-reading lessons in ways that differed one from another, and from a generally accepted framework (Ministry of Education, 2003a) designed to facilitate teaching that leads to processing. This finding does not suggest that a rigid orthodoxy need exist. However, adaptations to the framework are likely to have consequences for how effectively processing in reading can be facilitated during a lesson. Ford \& Opitz (2008) confirm that "variations in understandings can often lead to significant differences in how practices get implemented" (p. 311). An outcome of the Ready to Read revisions (Ministry of Education, 2014) is that the four key elements that make up the framework of a guided reading lesson have been clarified and are now defined as: (a) introducing the story, (b) monitoring the reading, (c) discussing the story after the first reading, and (d) after reading, practice, and reinforcement. A progressive delivery of these elements provides motivation and coherence for children, and an opportunity for the teacher to closely observe and respond to children's processing as they read independently (Fountas \& Pinnell, 1996).
From an analysis of guided reading in this study, more opportunities to teach for processing were evident in lessons that were most closely aligned to a generally accepted framework for guided reading (Ministry of Education, 2014) and where the elements were better sequenced for coherence. These lessons were generally 20 minutes or shorter and reflected momentum and energy that kept young learners motivated. While a moderate amount of time was spent on each element, the teacher devoted most time to monitoring each child's individual reading. Generally, where all elements were linked with an overriding emphasis on meaning, children's processing was observed to be more effective. Instructional conditions, such as these, are more likely to stimulate children's thinking and oral-language development (Johnston \& Allington, 1991), and are more conducive to children's development of processing over time if they are to manage textual complexities (Clay, 1991).

\section{Implications for learning and teaching}

While professional adaptive expertise (Timperley, 2011) is to be encouraged in general, altering a theorised and evidence-based framework for guided reading may disrupt the momentum and effectiveness of critical elements that support teaching for processing. Given the amount of instructional time allocated to guided reading in New Zealand schools, it is a concern that wellintended instructional efforts might constrain rather than facilitate children's processing, and possibly even delay early reading progress; a significant issue for the children most at risk of reading failure.

\section{Consider the language of instruction}

An analysis of teacher and student interactions during story introductions revealed that teaching prompts, directions, and questions were used to draw children's attention to print, rather than to meaning. This dichotomy seemed to be a compounding source of conflict and confusion for some beginning readers. Children with the least number of weeks of school attendance were in the early stages of forming hypotheses about letters, words, and messages; that is, the foundational learning needed for literacy processing (Doyle, 2015). They also found it difficult to conform to the participatory practices of the guided reading context (Phillips, McNaughton, \& MacDonald, 2004).

The teachers chose simple repetitive texts at the Magenta level or beginning guided reading. They viewed one line of repetitive print on each page as supportive for establishing directionality, one-to-one matching and concepts about print (e.g., first, last, words, letters, and 
sounds). As teachers introduced stories, their language assumed children could draw on instructional terms and protocols, in combination with reserves of foundational learning. Some examples included directionality ("Turn to the last page." "Where do we start?"), word identification ("Can you find the word 'bees'?" "What do you think that word says?"), letter recognition ("What's our letter of the week?" "Why do we have a capital letter?") and sounds ("Remember 'th' when you put your tongue out"). Even more complex combinations were used on occasions, such as letter and sound relationships ("What sound does an /s/ make?"), letter/ sounds and directionality ("If it was 'clown' what would it start with?") and words within words ("Can you see 'am' in there?"- "Sam”). In general, the same teaching was aimed at all children in the group, irrespective of competencies and their length of time at school.

\section{Implications for learning and teaching}

The examples illustrate the complexity of instructional dialogue. The specialised terms and routines can be a source of mismatch and confusion for novice learners, especially for children from a language background other than English. Five-year-old children, at entry to school, have had little time to understand about what it is the teacher means or what is expected of them as learners. Phillips et al. (2004) described how teachers who participated in significant professional development learnt to use carefully orchestrated instructional language that contributed to shifts in children's reading achievement. Clay (2001) argued that most children are likely to get underway with reading even under difficult instructional conditions. Nonetheless, the challenges of instructional language, combined with the complex idiosyncrasies in the beginning guided reading context, undoubtedly pose multifaceted challenges for children. This is particularly so for priority learners who benefit from instruction that resolves, rather than compounds, confusions about foundational knowledge and what is required to be a literacy learner (Johnston \& Allington, 1991). This study adds to evidence of a further layer of complexity in guided reading by illustrating that instructional dialogue may inadvertently impede children's literacy progress.

\section{Conclusion}

Guided reading is the core instructional approach for young children's development of processing systems for reading in classrooms in Aotearoa New Zealand. Surprisingly, little empirical research has been conducted nationally or internationally on this central aspect of literacy strategy. Our focus on new-entrant children's development of processing systems was intentionally narrow given the emphasis on processes and strategies in guided reading within The New Zealand Curriculum (Ministry of Education, 2007) and Ready to Read revisions (2014).

The study highlighted the special challenges of introducing the newest school entrants to guided reading. To ensure early and ongoing success with learning to read, teachers need to support children's foundational learning (discovering concepts about print, knowledge of the written code and seeing the symbols [letters] and patterns of symbols in print, and looking at print according to the directional rules of our written language). Typically, the "everyday" range of literacy approaches in New Zealand classrooms, such as shared reading and writing, language experience, and regular reading aloud (Ministry of Education, 2003a) coupled with rich classroom conversation (Ministry of Education, 2009a), permit these foundational skills to develop in ways that will engage, encourage, and extend young children's early literacy success. Noticing and responding to the learning routes of individual children may lead teachers to exercise caution in their decision to introduce children to guided reading, an intensive form of reading instruction, in their first days of school.

The findings reported in the previous section are succinctly summarised in the following brief statements, which may be used for professional inquiry by individual teachers, collegial group discussions, or a stepping-off point for future research.

- Children's early development of processing systems for reading may be at risk if they are plunged prematurely into guided reading at entry to school.

- Understanding and skill is required to introduce a story to new-entrant children in a manner that will lead to children's independent reading of the new text.

- Guided reading lessons should be structured to facilitate opportunities to teach for processing in reading.

- Children's early development of processing systems for reading may be at risk if they become confused by the teacher's language of instruction in beginning guided reading.

The clarifications around guided reading emerging from the review (Ministry of Education, 2014) were designed to influence teachers' knowledge and understandings of this key instructional approach and, where necessary, change teacher practices. The teacher support material for the newly published Ready to Read texts, accompanied by intermittent communications to schools however, may be insufficient to support the significant changes they recommend. Opportunities for teachers to engage in professional learning to examine the revisions in the 
light of their own practice is paramount, and continuous professional support is needed to ensure that this instructional approach achieves its powerful potential. Perhaps Clay's (2010) hypothesis that a child's slow pace of progress in the first year of school may be the result of becoming puzzled and confused by a too-hasty introduction to the complexities of the written code, may signal the need for more extensive contemporary investigation.

Madalyn and Amber, introduced at the beginning of this article, had time to make transitions to the formal literacy instruction of the classroom and bring their understandings about literacy learning to the new context of guided reading. Prepared in the rich ground of those early activities, they have established foundational learning that can propel them forward. As they engage with Katy, also introduced at the beginning of this article, they anticipate the story outcomes, make predictions about the language and vocabulary, and notice the links she makes to print. With meaning as a guide, they are well-prepared to problem solve their way through the new story independently.

Other young learners, particularly those described as priority students, are equally deserving of teachers who not only have the best of intentions, but who possess a well-theorised and informed understanding of when, and how, to introduce guided reading as the express route to independence in reading.

\section{Notes}

1 All names in the article are pseudonyms.

2 This article is based on Aitken's (2016) master's thesis.

\section{References}

Aitken, J. A. (2016). The development of children's processing systems for reading: The influence of guided reading in the first year of school. Unpublished master's thesis, The University of Auckland.

Aitken, J., Gaffney, J. S., \& Villers, H. (2017, December). Guided reading: In pursuit of early literacy processing. Paper presented at the Literacy Research Association, Tampa, Florida.

Biddulph, J. (2002). The guided reading approach: Theory and research. Wellington: Learning Media.

Boocock, C. (2012). Comparing the effects of expository and narrative texts on teacher instruction and child processing in junior guided reading. Unpublished master's thesis, The University of Auckland.

Clay, M. M. (1991). Becoming literate: The construction of inner control. Auckland: Heinemann.

Clay, M. M. (2001). Change over time in children's literacy development. Auckland: Heinemann.
Clay, M. M. (2005). An observation survey of early literacy achievement. Auckland: Pearson.

Clay, M. M. (2010). The puzzling code. Auckland: Pearson.

Clay, M. M. (2014). By different paths to common outcomes: Literacy learning and teaching. Auckland: The Marie Clay Literacy Trust.

Doyle, M. A. (2015, Spring). Marie Clay's theoretical perspectives and powerful messages for teachers. Journal of Reading Recovery, 15-23.

Education Review Office. (2009). Reading and writing in years 1 and 2. Wellington: Author.

Education Review Office. (2012). Evaluation at a glance: Priority learners in New Zealand schools. Wellington: Education Review Office.

Ford, M. P. \& Opitz, M, F. (2008). A national survey of guided reading practices: What we can learn from primary teachers. Literacy Research and Instruction, 47, 309-331. https://doi. org/10.1080/19388070802332895

Fountas, I. C., \& Pinnell, G. S. (1996). Guided reading: Good first teaching for all children. Portsmouth, NH: Heinemann.

Fountas, I. C., \& Pinnell, G. S. (2012). The romance and the reality. The Reading Teacher, 66(4), 268-284. https://doi. org/10.1002/TRTR.01123

Hancock, K. (2015). Ready to go with ready to read. Literacy Forum New Zealand, 30(2), 5-11.

Jeurissen, M. J., \& Burt, J. (2015). English language learners and the reading task board. Literacy Forum NZ, 30(3), 19-30.

Johnston, P., \& Allington, R. (1991). Remediation. In R. Barr, M. L. Kamil, P. Mosenthal, \& P. D. Pearson (Eds.), Handbook of Reading Research, 11, 984-1012.

McDowall, S. (2010). Literacy teaching and learning for the 21st century: Bridging the theory to practice gap. Set: Research Information for Teachers, (2), 2-9.

McKay, M. R. (2004). An investigation of guided reading with beginning readers in the national literacy strategy (1998-2002). Unpublished master's thesis, University of Leeds, UK.

McNaughton, S. (2002). Meeting of minds. Wellington: Learning Media.

McNaughton, S. (2011). Sensitive events in literacy development. In J. Parr, H. Hedges, \& S. May (Eds.), Changing trajectories of teaching and learning. Wellington: NZCER Press.

McNaughton, S., Phillips, G., \& MacDonald, S. (2000). Curriculum channels and literacy development over the first year of instruction. New Zealand Journal of Educational Studies, 35(1), 49-59. https://doi.org/10.1207/ s15548430j1r3502_2

McNaughton, S., Phillips, G., \& MacDonald, S. (2003). Profiling teaching and learning needs in beginning literacy instruction: The case of children in low decile schools in New Zealand. Journal of Literacy Research, 35(2), 703-730.

Ministry of Education. (2002). Guided reading: Years 1-4. Wellington: Learning Media. 
Ministry of Education. (2003a). Effective literacy practice in years 1 to 4. Wellington: Learning Media.

Ministry of Education. (2003b). Quality teaching for diverse children in schooling: Best evidence synthesis. Wellington: Author.

Ministry of Education. (2009a). Learning through talk: Oral language in Years 1 to 3. Wellington: Learning Media.

Ministry of Education. (2009b). The New Zealand curriculum: Reading and writing standards for years $1-8$. Wellington: Learning Media.

Ministry of Education. (2010). The literacy learning progressions: Meeting the reading and writing demands of the curriculum. Wellington: Learning Media.

Ministry of Education. (2013a, December). Happy birthday ready to read. Wellington: Lift Education.

Ministry of Education. (2013b). Ka hikitia-accelerating success: The Mãori education strategy 2013-2017. Wellington: Author.

Ministry of Education. (2014). Ready to Read review webinar. Retrieved from http://literacyonline. tki.org.nz/LiteracyOnline/News/Ready-to-Read-review-webinar

Phillips, G., McNaughton, S., \& MacDonald, S. (2004). Managing the mismatch: Enhancing early literacy progress for children with diverse language and cultural identities in mainstream urban schools in New Zealand. Journal of Educational Psychology, 96(2), 309-323. https://doi. org/10.1037/0022-0663.96.2.309

Richardson, J. (2009). The next step in guided reading. New York, NY: Scholastic.

Rubie-Davies, C. (2015). Becoming a high expectation teacher: Raising the bar. New York, NY: Routledge.

Schwartz, R. M. (2005). Decisions, decisions: Responding to primary students during guided reading. The Reading Teacher, 58(5), 436-443. https://doi.org/10.1598/RT.58.5.3

Smith, J. W. A., \& Elley, W. B. (1997). Reading instruction techniques. In How Children Learn to Read (pp. 31-44). Auckland: Addison Wesley Longman.

Stake, R. E. (2010). Qualitative research: Studying how things work. New York, NY: The Guilford Press.

Tunmer, W. E., Chapman, J. W., Greany, K.T., Prochnow, J.E., \& Arrow, A.W. (2013). Why the New Zealand National Literacy Strategy has failed and what can be done about it: Evidence from the Progress in International Reading Literacy Study (PIRLS) 2011 and Reading Recovery monitoring reports. Australian Journal of Learning Difficulties, 18(2), 139-180.

Timperley, H. S. (2011). Realising the power of professional learning. Maidenhead, UK: McGraw-Hill.
Judy Aitken is a Reading Recovery trainer and tutor, employed by the University of Auckland. As a trainer she works alongside the New Zealand Reading Recovery Project Director to support the effective implementation of Reading Recovery nationwide. As a tutor she trains teachers and supports trained teachers throughout the Manawatū, and teaches Reading Recovery children. Her focus on early literacy processing led to the master's research that underpinned this article.

Email: judy.aitken@auckland.ac.nz

Helen Villers is a senior lecturer in the Faculty of Education and Social Work at the University of Auckland. Her teaching and research are focused on critical sociocultural and pedagogical issues in languages, literacy / literacies, and children's literature. She teaches in postgraduate and undergraduate contexts, and is particularly interested in how literacy theories and pedagogies might be enhanced through school-university practicum partnerships.

Email: h.villers@auckland.ac.nz

Janet S. Gaffney is Professor of Educational Psychology-Literacy and Director of the Marie Clay Research Centre in the Faculty of Education and Social Work at the University of Auckland. Jan's research on literacy learning and teaching, and teacher leadership has led to the development of collaborative and innovative teacher leaders and teachers who view children's learning as the centripetal force that drives their thinking and actions. She has a dual background in educational psychology and special education and has extensive teaching experience in communities with indigenous populations. Email: janet.gaffney@auckland.ac.nz 